
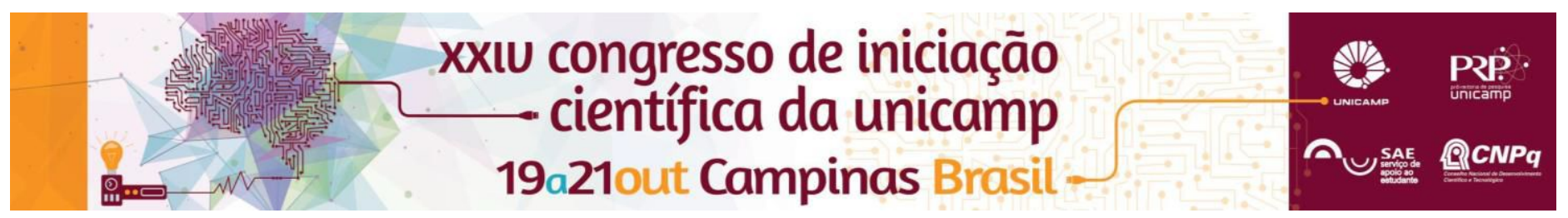

\title{
Estudo das interações de raios cósmicos de altíssimas energias em sua propagação no meio intergaláctico
}

\author{
Gabriel P. Alves*, Carola Dobrigkeit.
}

\section{Resumo}

Quando considerados os efeitos de longa distância na propagação de raios cósmicos ultra-energéticos desde suas fontes até a Terra, percebe-se a interação destes raios com a radiação cósmica de fundo (RCF). Processos que aparentemente não ocorreriam devido à baixa energia dos fótons da RCF, mostram-se possíveis quando analisados a partir do referencial de repouso do raio cósmico. Interações dos raios com a RCF, tais como produção de pares elétron-pósitron e fotoprodução de píons, são observadas, além da perda de energia devido à expansão adiabática do universo.

\section{Palavras-chave}

Raios cósmicos, propagação, Observatório Pierre Auger.

\section{Introdução}

Raios cósmicos são partículas ultra-energéticas que são produzidas no espaço exterior e se propagam no meio galáctico e intergaláctico podendo chegar à Terra. Tipicamente possuem energia superior a $10^{9} \mathrm{eV}$.

Em comparação às partículas de menor energia, pouco se sabe sobre a origem das partículas de altíssimas energias, até mesmo superiores a $5 \times 10^{19} \mathrm{eV}$, devido à baixa frequência com que são detectadas na Terra. Uma das explicações possíveis para este fato é a de que um fluxo de raios cósmicos ultra-energéticos interagiria com a radiação cósmica de fundo (RCF) produzindo píons, via ressonância $\Delta$. Esta explicação é conhecida como corte GZK, previsto por Greisen e, independentemente, por Zatsepin e Kuz'min $[1,2]$. A continuidade deste processo levaria a uma atenuação do fluxo de raios cósmicos, bem como criaria um horizonte além do qual partículas ultra-energéticas que percorrem distâncias superiores a $100 \mathrm{Mpc}$ não poderiam chegar à Terra.

Com a construção de grandes experimentos, como o Observatório Pierre Auger, um melhor entendimento sobre questões como as que dizem respeito à composição de partículas de altíssima energia pode ser obtido [3]. Desde então, uma grande quantidade destas partículas foram observadas, o que gera aparente contradição com o corte GZK e o torna objeto de discussão na comunidade científica.

Na luz deste debate, o objetivo do presente projeto é estudar a propagação de raios cósmicos de altíssimas energias pelo meio intergaláctico e os respectivos mecanismos de perda de energia que servem de base para a formulação da hipótese do corte GKZ, dentre estes a produção de pares elétron-pósitron, a fotoprodução de píons e a expansão adiabática do Universo.

\section{Resultados e Discussão}

Uma hipótese inicial razoável a ser feita é a de que as partículas de altíssimas energias são prótons. O processo pelo qual interagem com a RCF é explicado por um mecanismo puramente relativístico.

Se considerarmos como $S$ o referencial em que a RCF é isotrópica e $S^{\prime}$ o referencial de repouso do próton, então em $S^{\prime}$, a energia $E^{\prime}$ e o ângulo de incidência $\theta^{\prime}$ são dados pelas seguintes relações:

$$
\begin{aligned}
& E^{\prime}=\gamma E(1+\beta \cos \theta) \\
& \tan \theta^{\prime}=\frac{\sin \theta}{\gamma(\cos \theta+\beta)},
\end{aligned}
$$

onde $r$ é o fator de Lorentz, $E$ e $\theta$ são, respectivamente, a energia e o ângulo de incidência em $S$ e $\beta=v / c$, onde $v$ é a velocidade do próton em $S$ e $c$ é a velocidade da luz no vácuo.

Dessa maneira, para um próton de altíssima energia, um fóton na faixa de micro-ondas da RCF é visto como um raio gama em seu referencial, como esquematizado na figura 1.

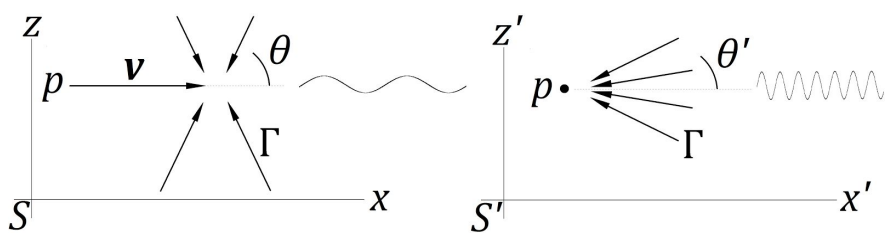

Figura 1. Representação da interação do próton $p$ com o fóton $\Gamma$ da RCF. No referencial $S$ a RCF é vista como uma radiação isotrópica de micro-ondas. Em $S^{\prime}$, os fótons $\Gamma$ interagem quase que paralelamente à direção de propagação de $p$.

As interações recorrentes em $S^{\prime}$ passam a ter, portanto, energia superior ao mínimo para a produção de pares elétron-pósitron e fotoprodução de píons, processos estes cujo estudo ainda está sendo concluído pelo aluno.

\section{Conclusões}

Uma distribuição isotrópica da RCF é vista colimada no referencial de repouso da partícula ultra-energética. A frequência da RCF é também distorcida: em $S^{\prime}$ a radiação de fundo de micro-ondas é vista como radiação gama, capaz de interagir via produção de pares e fotoprodução de píons com a partícula de energia ultra-alta. Conforme a distância de propagação do raio cósmico aumenta, a continuidade dos processos de perda de energia atenua o fluxo no intervalo de altíssimas energias.

[1] - K. Greisen, End to the Cosmic-Ray Spectrum?, Physical Review Letters 161966748.

[2] - G. T. Zatsepin, V. A. Kuz'min, Upper limit of the spectrum of cosmic rays, Soviet Physics, JETP Letters 4196678.

[3] - The Pierre Auger Collaboration, Depths of Maximum of Air-Shower Profiles at the Pierre Auger Observatory: Composition Implications, Physical Review D 90, 1220062014. 